\title{
STELLITE COATING DEPOSITED BY DIRECTED ENERGY DEPOSITION
}

\author{
1'Jaroslav VAVŘíK, 'Tatána HRBÁČKOVÁ, ${ }^{1}$ Pavel SALVETR, ${ }^{1}$ Michal BRÁZDA
}

${ }^{1}$ COMTES FHT, Dobřany, Czech Republic, EU, jvavrik@comteshft.cz

https://doi.org/10.37904/metal.2020.3559

\begin{abstract}
This paper explores a protective stellite coating on 1.4922 martensitic steel. Stellite coatings are often used to improve the properties of the part's surface. The microstructure of the sample was analysed and its hardness measured. Protective coatings enhance mechanical and corrosion properties of the substrate, and thus extend the life of the respective part. They can be created by galvanizing, ion implantation, thermal spraying, or by more recent methods, such as laser cladding, DED (directed energy deposition) and others. DED is one of the metal deposition processes that fall in the AM category (additive manufacturing). It was used to deposit the protective coating in the present study. DED is an evolving technology which is suitable not only for prototype development, but also for promising applications involving surface treatment and repairs of functional parts. DED uses a laser beam as a thermal source to melt powder which is blown concentrically with the laser beam and the protective gas. The unique advantage of this method is a very good cohesion and bonding between the substrate and the deposited layer with a smaller HAZ (heat-affected zone). It produces comparatively few inhomogeneities and defects, which makes it a promising technique for protective layer applications. Stellite was chosen as a protective coating material because this group of alloys exhibits excellent properties such as high wear resistance, abrasion resistance, superior corrosion resistance and erosion resistance. These are relevant in many industrial sectors, such as power generation, aerospace and others. Stellite 21 was used in the present study.
\end{abstract}

Keywords: Coating, Directed Energy Deposition, Stellite 21, Microstructure

\section{INTRODUCTION}

There are many surface coating techniques, including galvanizing, ion implantation, thermal spraying and more recent ones, such as laser cladding, DED (Directed Energy Deposition) and many others. Each of them has its strengths as well as weaknesses $[1,2,3]$. This paper deals with the DED process. DED is one of the many processes which are categorized as additive manufacturing (AM). Some other AM methods include SLM (Selective Laser Melting), Binder Jetting or Sheet Lamination [2,3]. DED is a promising technique which can produce objects of various shapes unachievable by conventional production. Unlike many other AM techniques which can only generate entire new parts, DED can be used to deposit material on pre-existing substrates, such as damaged engineering parts which needs a repair or parts to receive protective coatings. Using DED, various powders (with different chemical compositions, and particle sizes and shapes) can be deposited and combined easily and concurrently. This opens a possibility for building graded materials consisting of many different alloys for a wide range of applications. Such combinations may include Ti6AI4V with TiC, Invar with $\mathrm{TiC}$ or $316 \mathrm{~L}$ stainless steel with $\mathrm{Cu}$ and many others $[2,4]$. It is very difficult or almost impossible to combine these materials in one step by conventional manufacturing methods. In DED, powder feedstock flows through a nozzle and is melted by a fibre laser beam under a protective atmosphere (usually argon gas). The melted powder is rapidly cooled by losing heat to both the substrate and the protective atmosphere. The build is printed layer by layer. 
Stellites are Co-based alloys with the superior performance provided by their high mechanical properties, outstanding corrosion resistance, wear, creep and erosion resistance and others. They find use in specific industries, such as nuclear power generation, automotive, paper and pulp, chemical, petrochemical and aircraft industries, as well as in medical surgery, bone implants and others. [5,6,7]. There are two groups of stellites which differ in their molybdenum or tungsten content [5]. Both Mo and $W$ improve the matrix strength and create hard and stable carbides, leading to significantly higher hardness, ultimate tensile strength and wear resistance [5]. The key element in stellite is cobalt. It has a CPH (closed packed hexagonal) structure which persists until the temperature of $421{ }^{\circ} \mathrm{C}$. Above $421{ }^{\circ} \mathrm{C}$, the structure transforms to FCC (face cubic centered) crystal lattice $[5,6,8]$. Thanks to $\mathrm{Co}$, stellites have high strength at elevated temperatures and high corrosion resistance [5,8]. Chromium, the main alloying element in stellites, helps to increase corrosion and wear resistance. Chromium forms very hard carbides. It also has superior resistance against galling and cavitation [5,6]. All these facts suggest that a stellite surface coating might be a very promising alternative to other alloys. Stellite 21 was chosen for this study because it possesses the above-listed good properties and has very favourable friction coefficient and resistance against galling even at higher temperatures [9]. Consequently, it can sustain extreme conditions and help to solve difficulties with erosion or cavitation in some industries.

The sample on which a protective coating of stellite was deposited was 1.4922 martensitic stainless steel. This type of steel is often used where creep resistance and heat resistance are required, such as in power plants, specific types of pipes, tanks and similar applications $[10,11]$. Stellite coating would improve its utility properties and extend its lifetime in most environments.

\section{MATERIALS AND METHODS}

The deposition process took place in Insstek MX-600, a metal 3D printer which uses the DED principle. It has a 2-kW yttrium fibre laser and four powder feeders for using four different powders in a single deposition process. Its motion is controlled in $3+2$ axes.

The chemical compositions of the base material sample and the powder are given in Table 1. The composition of the sample was measured using Bruker Q4 Tasman optical spectrometer. The material of the sample is martensitic steel. The powder used for deposition was Stellite 21 produced by VDM Metals International $\mathrm{GmbH}$ Company. Its particle size is in the range of $53-150 \mu \mathrm{m}$.

Table 1 Chemical composition of stellite powder and sample in wt. \%

\begin{tabular}{|c|c|c|c|c|c|c|c|c|}
\hline Element & Co & Cr & Ni & Si & Mo & Fe & C & \\
\hline Stellite 21 & 64.9 & 28.9 & 0.02 & 0.01 & 6.0 & 0.03 & $<0.002$ & \\
\hline Element & $\mathbf{F e}$ & $\mathbf{C}$ & $\mathbf{C r}$ & $\mathbf{N i}$ & $\mathbf{M n}$ & $\mathbf{S i}$ & $\mathbf{M o}$ & $\mathbf{V}$ \\
\hline Sample & $\mathrm{bal}$ & 0.15 & 13.1 & 0.4 & 0.5 & 0.3 & 0.7 & 0.2 \\
\hline
\end{tabular}

A model of the coating deposited on the sample surface was created and sliced using the Magic software. It had a thickness of $4 \mathrm{~mm}$ to account for possible changes in hardness with increasing distance from the sample. An illustration of the coating and the base material is shown in Figure 1. The procedure referred to as deposition strategy was CF ZZ ( $\mathrm{C}=$ contour, $\mathrm{F}=$ filling, $\mathrm{ZZ}=\mathrm{zigzag}$ ). The direction of the deposition path alternated between layers by $90^{\circ}$. The thickness of a single layer was $0.25 \mathrm{~mm}$ and the width of the track was $0.8 \mathrm{~mm}$. The hatching distance was $0.5 \mathrm{~mm}$. The average laser power used for deposition was around $400 \mathrm{~W}$. Argon gas as a protective atmosphere is a necessity to avoid oxidation during printing. A 5.0-purity gas was flowing through a nozzle to the area around meltpool.

The microstructure was observed under an optical microscope (Nikon ECLIPSE MA200) and in an SEM (scanning electron microscope, JEOL IT 500 HR). Hardness HV1 was measured using Struers Durascan 50. 


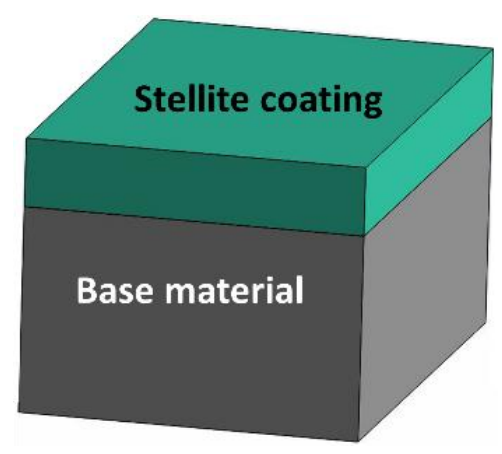

Figure 1 Illustration of a protective coating on the base material

\section{RESULTS}

Microstructural observation was carried out along Z-axis in order to study the HAZ and the joint between the coating and the substrate. The entire coating on the substrate is shown in Figure 2A. In Figure 2B, there is a microstructure which is typical of 3D-printed materials and consists of individual meltpools. This micrograph was taken in the centre of the substrate sample. The individual layers are readily distinguishable. The transition region between the base material and the coating shows good quality with no visible cracks, pores or other defects, as documented in Figure 2C-D. Good adhesion and chemical bonding are very important. Otherwise, the coating could separate easily and fail to perform its function. It would also impair the mechanical properties and fatigue behaviour of the entire part. The thickness of the HAZ is approximately $110 \mu \mathrm{m}$, as shown in Figure 2D. Detailed investigation by SEM, as documented in Figure 3A-B, revealed a visible cellular structure, which is also typical of DED products.
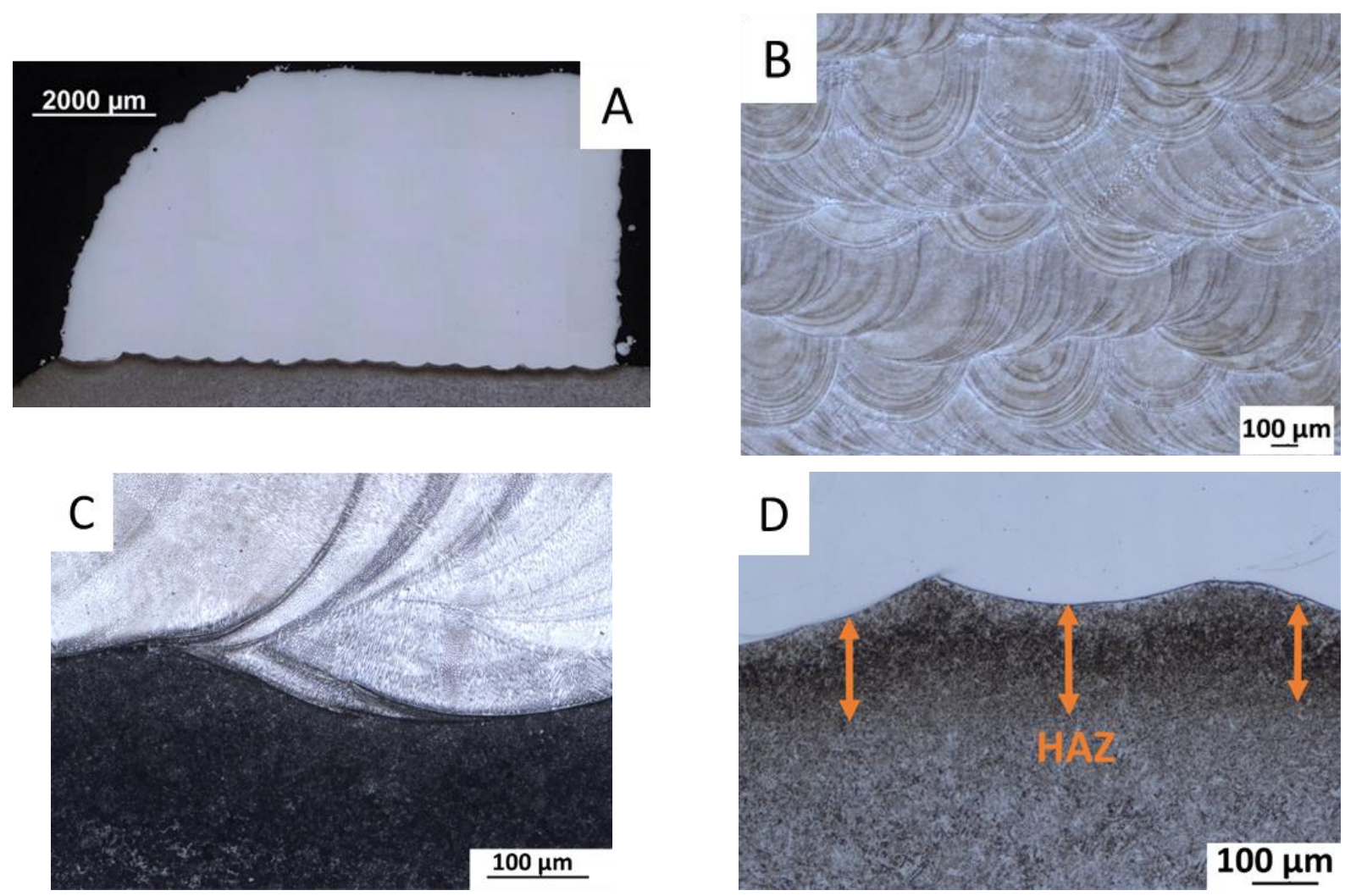

Figure 2 Microstructure of the coating: A) OM (optical micrograph) of the coating, B) OM of meltpool structure in the middle of the coating, C) OM of the transition area, D) OM of the HAZ 

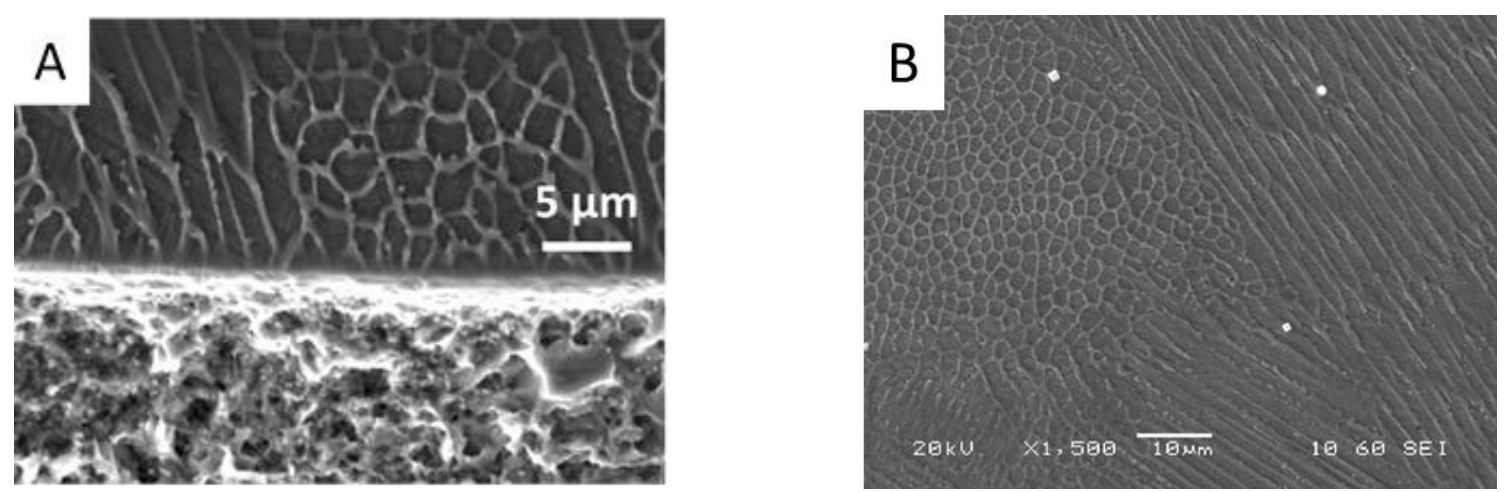

Figure 3 Microstructure of the coating: A) SEM (scanning electron micrograph) of the transition area, B) SEM of the coating
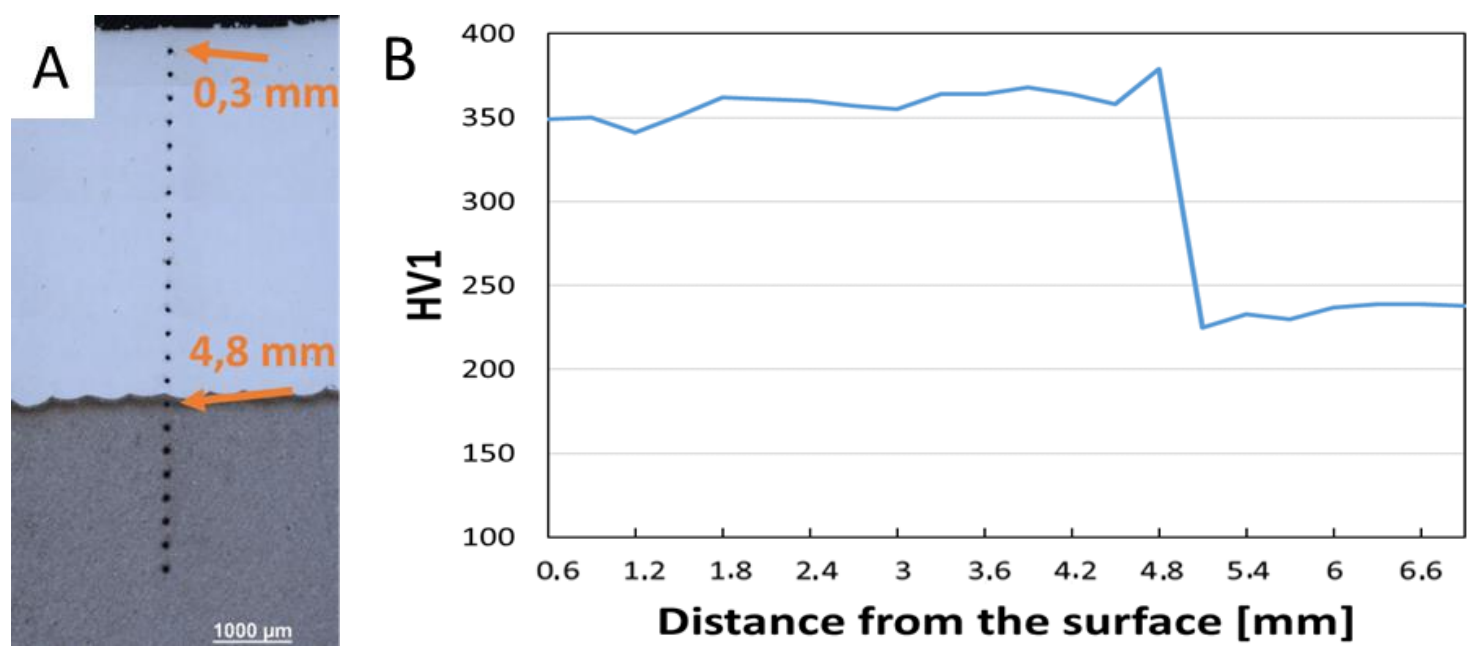

Figure 4 A) Hardness indentations, B) depth profile of HV1 hardness vs. distance from the surface

Indentations from hardness measurement taken from the surface of the coating to the interior of the sample are shown in Figure 4A. The plot of hardness profile is presented in Figure 4B. In the coating, it varies around $350 \mathrm{HV} 1$. In the base material, the values are around 230-240 HV1. The highest hardness was found in the transition area (HAZ): 379 HV1. The same finding was reported by Karmakar et al. [1][1]. This is probably due to the rapid cooling of the first layer deposited on the substrate. The surface of the substrate might have been partly melted and diluted by the laser and then cooled rapidly, causing martensite to form. Then, as the additive process continued, martensite was heat-treated by the heat from subsequently-deposited layers. This could also lead to higher stresses and cracks, inhomogeneities and other flaws. On the other hand, no cracks or anything that could impair cohesion between the layers and bonding in the transition region were found.

\section{CONCLUSION}

In this experimental study, a protective stellite coating was deposited by DED on a sample of martensitic steel. Microstructural analysis revealed good cohesion between the base material and the coating. No cracks, pores or other flaws were found, which could impair the cohesion in the transition area. The thickness of the HAZ was approximately $110 \mu \mathrm{m}$. High hardness was found in the HAZ. The coating significantly improved the mechanical properties of the base material: from $240 \mathrm{HV} 1$ to $350 \mathrm{HV} 1$. Mechanical properties (tensile strength, ductility, etc.) and corrosion resistance will be studied further to confirm the usability of this deposition method for stellite alloys in specific industrial sectors. 


\section{ACKNOWLEDGEMENTS}

\section{This paper was developed thanks to the project entitled Pre-Application Research of Functionally Graduated}

\section{Materials by Additive Technologies, No.: CZ.02.1.01/0.0/0.0/17_048/0007350, financed by the Ministry of Education of the Czech Republic.}

\section{REFERENCES}

[1] KARMAKAR D. P., MUVVALA G., NATH A. K. Effect of scan strategy and heat input on the shear strength of laser cladded Stellite 21 layers on AISI H13 tool steel in as-deposited and heat treated conditions. Surface and Coatings Technology. 2020, vol. 384, https://doi.org/10.1016/j.surfcoat.2019.125331.

[2] ZHANG C., CHEN F., HUANG Z., JIA M., CHEN G., YE Y., LIN Y., LIU W., CHEN B., SHEN Q., ZHANG L., LAVERNIA E. J. Additive manufacturing of functionally graded materials: A review. Materials Science and Engineering: A. 2019, vol. 764, https://doi.org/10.1016/i.msea.2019.138209.

[3] NGO T. D., KASHANI A., IMBALZANO G., NGUYEN K. T., HUI D. Additive manufacturing (3D printing): A review of materials, methods, applications and challenges. Composites Part B: Engineering. 2018, vol. 143, pp. 172-196, https://doi.org/10.1016/j.compositesb.2018.02.012.

[4] YAKOVLEV A., TRUNOVA E., GREVEY D., PILLOZ M., SMUROV I. Laser-assisted direct manufacturing of functionally graded 3D objects. Surface and Coatings Technology. 2005, vol. 190, no. 1, pp. 15-24, https://doi.org/10.1016/j.surfcoat.2004.07.070.

[5] HASAN M., MAZID A., CLEGG R. The Basics of Stellites in Machining Perspective. International Journal of Engineering Materials and Manufacture. 2016, vol. 1, no. 2, pp. 35-50,

https://doi.org/10.26776/ijemm.01.02.2016.01.

[6] MARTI A. Cobalt-base alloys used in bone surgery. Injury. 2000, vol. 31, no. 4, pp. D18-D21, https://doi.org/10.1016/s0020-1383(00)80018-2.

[7] SHOKRANI A., DHOKIA V., NEWMAN S. T. Environmentally conscious machining of difficult-to-machine materials with regard to cutting fluids. International Journal of Machine Tools and Manufacture. 2012, vol. 57, pp. 83-101, https://doi.org/10.1016/j.ijmachtools.2012.02.002.

[8] CROOK P. Cobalt and Cobalt Alloys. In: Properties and Selection: Nonferrous Alloys and Special-Purpose Materials, Vol 2, ASM Handbook, ASM International, 1990, p 446-454, https://doi.org/10.31399/asm.hb.v02.a0001073.

[9] PERSSON D., JACOBSON S., HOGMARK S. Effect of temperature on friction and galling of laser processed Norem 02 and Stellite 21. Wear. 2003, vol. 255, no. 1-6, pp. 458-503, https://doi.org/10.1016/S00431648(03)00122-4.

[10] M. Woite GmbH. Material No.: 1.4922. [Online]. 2012. [Viewed 2020-06-02]. Available from: http://www.woiteedelstahl.com/14922en.html.

[11] Total Materia. [Online]. 2020. [Viewed 2020-06-02]. Available from: https://search.totalmateria.com/Search/SubgroupList/1395262. 